\title{
Poly(styrene oxide)-poly(ethylene oxide) block copolymers: From “classical” chemotherapeutic nanocarriers to active cell-response inducers
}

\author{
A. Cambón ${ }^{\mathrm{a} \infty}$, A. Rey-Rico ${ }^{\text {bo }}$, S. Barbosa ${ }^{\mathrm{a}^{*}}$, J. F. A. Soltero ${ }^{\mathrm{c}}$, S. G. Yeates ${ }^{\mathrm{d}}$, J. Brea $^{\mathrm{e}}$, \\ M.I. Loza ${ }^{\mathrm{e}}$, C. Alvarez-Lorenzo ${ }^{\mathrm{b}, \mathrm{e}}$, A. Concheiro ${ }^{\mathrm{b}, \mathrm{e}}$, P. Taboada ${ }^{\mathrm{a}^{*}}$, V. Mosquera ${ }^{\mathrm{a}}$. \\ ${ }^{a}$ Grupo de Física de Coloides y Polímeros, Departamento de Física de la Materia \\ Condensada; ${ }^{b}$ Departamento de Farmacia y Tecnología Farmacéutica; ${ }^{e}$ Instituto de \\ Farmacia Industrial, Universidad de Santiago de Compostela, 15782-Santiago de \\ Compostela, Spain. \\ ${ }^{c}$ Departamento de Ingeniería Química, Universidad de Guadalajara, Boul. M. García \\ Barragán \#1451, Guadalajara, Jalisco 44430, México \\ ${ }^{d}$ Organic Materials Innovation Center, School of Chemistry, University of Manchester, \\ Manchester M13 9PL, United Kingdom \\ ${ }^{\infty}$ These authors contributed equally to this work \\ *Authors to whom correspondence should be addressed: \\ E-mail: silvia.barbosa@usc.es; Tel./Fax: 0034881814115/0034881814112 \\ E-mail: pablo.taboada@usc.es; Tel./Fax: 0034881814111/0034881814112
}

\begin{abstract}
Two poly(styrene oxide)-poly(ethylene oxide) (PSO-PEO) triblock copolymers with different chain lengths were analyzed as potential chemotherapeutic nanocarriers, and their ability to inhibit the P-glycoprotein (P-gp) efflux pump in a multidrug resistant (MDR) cell line were measured in order to establish possible cell-responses induced by the presence of the copolymer molecules. Thus, $\mathrm{EO}_{33} \mathrm{SO}_{14} \mathrm{EO}_{33}$ and $\mathrm{EO}_{38} \mathrm{SO}_{10} \mathrm{EO}_{38}$ polymeric micelles were tested regarding doxorubicin (DOXO) entrapment efficiency (solubilisation test), physical stability (DLS), cytocompatibility (fibroblasts), release profiles at various pHs (in vitro tests), as well as P-gp inhibition and evasion and cytotoxicity of the DOXO-loaded micelles in an ovarian MDR NCI-ADR/RES cell line and in DOXO-sensitive MCF-7 cells. $\mathrm{EO}_{33} \mathrm{SO}_{14} \mathrm{EO}_{33}$ and $\mathrm{EO}_{38} \mathrm{SO}_{10} \mathrm{EO}_{38}$ formed spherical micelles $(\sim 13 \mathrm{~nm})$ at lower concentration than other copolymers under clinical evaluation (e.g. Pluronic ${ }^{\circledR}$ ), exhibited 0.2 to $1.8 \%$ loading capacity, enhancing more than 60 times drug apparent solubility, and retained the cargo for long time. The copolymer unimers inhibited P-gp ATPase activity in a similar way as Pluronic P85, favoring DOXO accumulation in the resistant cell line, but not in the sensitive cell line. DOXO loaded in the micelles accumulated more slowly inside the cells, but caused greater cytotoxicity than free drug solutions in the NCI-ADR-RES cell line, which overexpressed P-gp. Hence, PSO-PEO block copolymers offer interesting features as new biological response modifiers to be used in the design of efficient nanocarriers for cancer chemotherapy.
\end{abstract}

Keywords: polymeric micelles; doxorubicin; drug delivery; cytotoxicity; pglycoprotein efflux pump; multidrug resistant cells. 


\section{Introduction}

Advances in materials science offer tremendous opportunities to develop novel nanocarriers able to improve the pharmacokinetics and the local bioavailability of a variety of drugs, apart from providing additional functionalities [1-4]. Among the diverse nanoparticulate systems suitable for encapsulating and delivering drugs, micelles formed by amphiphilic polymers occupy a relevant position [5,6]. Selfassembly of biocompatible copolymers consisting of two or more blocks with different hydrophobicity may result in the formation of micelles with a hydrophobic core and a hydrophilic shell. Copolymers bearing hydrophilic poly(ethylene oxide) (PEO) blocks lead to sterically stabilized micelles that show prolonged blood circulation, and passively accumulate in solid tumors [4]. The most widely studied amphiphilic copolymers are those composed of PEO and poly(propylene oxide) (PPO) blocks, particularly the linear and bifunctional poloxamers (Pluronics ${ }^{\circledR}$ ) and the X-shaped poloxamines $\left(\right.$ Tetronic $^{\circledR}$ ). PEO-PPO block copolymers have gained popularity over the last decades due to: i) their commercial availability; ii) proven fair solubilization capacity and sustained drug delivery; iii) high biocompatibility of most varieties; iv) inhibition of different efflux transporters overexpressed in multidrug resistant (MDR) cells; v) ability to enhance drug transport across cellular barriers; and vi) regulatory status, i.e., approval of some varieties by US FDA and EMA to be used in pharmaceutical formulations and medical devices [7-9]. Nevertheless, PEO-PPO block copolymers display several drawbacks, such as uncomplete micellization of unimers and limited drug solubility and colloidal stability upon dilution in the bloodstream particularly when the $\mathrm{EO} / \mathrm{PO}$ ratio is high.

To achieve a more efficient aggregation and micelle stability, a series of other block copolymer counterparts of similar architecture but with the PPO segment replaced 
by a more hydrophobic one such as poly(butylene oxide) (PBO), poly(styrene oxide) (PSO) or phenylglycidyl ether (PG) has been developed by the Attwood and Booth's group in collaboration with us during last years [10-13]. The micelles of these copolymers showed improved solubilization capacity and stability [11,14-15]. In particular, PSO-based block copolymers are of interest due to the wide availability of architectures and molecular weights [12], their ability to self-assemble into micelles of different shapes at very low concentrations depending on their relative block lengths [16], and their low glass transition temperature (ca. $40{ }^{\circ} \mathrm{C}$ ), which enables the incorporation of termolabile drugs $[11,17]$. Despite the micellization and solubilisation ability of some PSO-based copolymers have been previously studied $[10,12,13,16]$, as far as we know only one study has analysed the role of PSO-PEO copolymer micelles as carriers of an anticancer drug (docetaxel) [18]. Moreover, in contrast to the welldemonstrated inhibitory activity of several PEO-PPO Pluronic ${ }^{\circledR}$ and Tetronic ${ }^{\circledR}$ block copolymers against drug efflux transporters overexpressed in MDR cells [8,19-20], no reports are available about the potential capabilities of PSO-based copolymers as effluxpump inhibitors.

Hence, we evaluate the ability of copolymers $\mathrm{EO}_{33} \mathrm{SO}_{14} \mathrm{EO}_{33}$ and $\mathrm{EO}_{38} \mathrm{SO}_{10} \mathrm{EO}_{38}$ to dissolve and chemically protect doxorubicin (DOXO), analyzing the colloidal stability, the drug release profiles, the safety, and the in vitro efficacy of the drug-loaded polymeric micelles as an antitumoral formulation. The $\mathrm{EO} / \mathrm{SO}$ ratio and the block lengths of both copolymers were selected to attain an optimal compromise between chain solubility, micelle formation ability, and core size that lead to enhanced drug solubility, while ensuring renal clearance of unimers as required for non-biodegradable polymers [21]. Shorter PEO blocks, as those of $\mathrm{EO}_{10} \mathrm{SO}_{10} \mathrm{EO}_{10}[16]$, and longer PSO blocks compromise copolymer solubility. By contrast, longer PEO and shorter PSO 
blocks may lead to greater cmcs with the subsequent increase in material expense to solubilise the required amount of drug [12]. $\mathrm{EO}_{33} \mathrm{SO}_{14} \mathrm{EO}_{33}$ and $\mathrm{EO}_{38} \mathrm{SO}_{10} \mathrm{EO}_{38}$ may also help to elucidate the effect of copolymer architecture in solubilisation and controlled release performance by comparison with the data reported for PSO diblock copolymers [18]. On the other hand, the ability of the present copolymers to inhibit the Pglycoprotein (P-gp) efflux pump was investigated for the first time. DOXO accumulation in an in vitro model of MDR cell line with high expression of P-gp (ovarian tumor cell line NCI-ADR-RES) was evaluated and compared with that achieved in a non-resistant cell line (breast cancer cell line MCF-7). Moreover, the effect of the copolymers on P-gp ATPase activity was analyzed and compared to that

caused by Pluronic ${ }^{\circledR}$ P85, the most efficient cell sensitizing block copolymer so far described $[8,19]$. Overall, the results indicate that the micellar systems based on PSOPEO block copolymers improves DOXO encapsulation and its systemic delivery, resulting in lower cytotoxicity and enhanced chemotherapeutic activity by the combined effect of the controlled drug release and the inhibition of the P-gp efflux pump.

\section{Materials and methods}

2.1 Materials. $\mathrm{EO}_{33} \mathrm{SO}_{14} \mathrm{EO}_{33}$ and $\mathrm{EO}_{38} \mathrm{SO}_{10} \mathrm{EO}_{38}$ (Table 1) were synthesized as previously described [10]. Weight-averaged $\left(M_{w}\right)$ to number-averaged $\left(M_{n}\right)$ molecular weight ratios were determined at $25^{\circ} \mathrm{C}$ using a Waters gel permeation chromatography (GPC) system (Waters, Milford, MA). $M_{n}$ values were estimated from ${ }^{1} \mathrm{H}$ NMR spectra recorded on a Bruker ARX400 spectrometer (Bruker, Milton, ON, Canada). Pluronic ${ }^{\circledR}$ P85 was supplied by BASF (New Milford, CT, USA). Verapamil (VER), calcein AM, and doxorubicin hydrochloride (DOXO-HCl) were from Sigma-Aldrich. DOXO base for solubilisation inside copolymer micelles was obtained by means of aqueous 
precipitation of DOXO $\cdot \mathrm{HCl}(1 \mathrm{mg} / \mathrm{ml})$ adding triethylamine (three moles per drug mol) and methylene chloride. Hereinafter, DOXO refers to DOXO base. Water was double distilled and degassed before use. All other reagents were analytical grade.

Table 1. Molecular characteristics of the copolymers.

\begin{tabular}{lcccc}
\hline & $\mathrm{M}_{\mathrm{n}}{ }^{*}\left(\mathrm{~g} \mathrm{~mol}^{-1}\right)$ & $\begin{array}{c}\text { SO content* } \\
\text { (wt.\%) }\end{array}$ & $\mathrm{M}_{\mathrm{w}} / \mathrm{M}_{\mathrm{n}}{ }^{* *}$ & $\mathrm{M}_{\mathrm{w}}\left(\mathrm{g} \mathrm{mol}^{-1}\right)$ \\
\hline $\mathrm{EO}_{33} \mathrm{SO}_{14} \mathrm{EO}_{33}$ & 4790 & 40.0 & 1.01 & 4850 \\
$\mathrm{EO}_{38} \mathrm{SO}_{10} \mathrm{EO}_{38}$ & 5055 & 34.1 & 1.02 & 5130 \\
\hline
\end{tabular}

*Estimated from NMR data; **Determined by GPC; $M_{w}$ was calculated from $M_{n}$ and $M_{w} / M_{n}$ ratio. Uncertainty: $M_{n}$ to $\pm 3 \%$; wt $\%$ SO to $\pm 1 \%, M_{w} / M_{n}$ to \pm 0.01 .

2.2 Drug solubilisation. Solubilization of DOXO (intrinsic solubility in water $0.1-0.5$ $\left.\mathrm{mg} \mathrm{dm}{ }^{-3}\right)$ [22] in micellar copolymer solutions $(0.2 \mathrm{wt} \%)$ was tested in triplicate following a methodology previously reported [15] (see Supplementary Material).

2.3 Physical stability of the drug-loaded micelles upon dilution. DOXO micellar solutions were diluted (1/50) with either $0.01 \mathrm{M}$ phosphate buffer $\mathrm{pH} 7.4$ or cell culture medium with $10 \%$ FBS and incubated at $37{ }^{\circ} \mathrm{C}$, and the drug concentration was monitored over time by UV spectrophotometry. In parallel, changes in the size of drugloaded micelles were monitored by dynamic light scattering at $37{ }^{\circ} \mathrm{C}$ using an ALV5000F (ALV-GmbH, Germany) instrument with vertically polarized incident light $(\lambda=$ $488 \mathrm{~nm}$ ) supplied by a diode-pumped Nd:YAG solid-state laser (Coherent Inc., CA, USA) operated at $2 \mathrm{~W}$, and combined with an ALV SP-86 digital correlator (sampling time $25 \mathrm{~ns}$ to $100 \mathrm{~ms}$ ) as previously reported [10] (see Supplementary Material).

2.4 In vitro DOXO release. Aliquots $(4 \mathrm{~mL})$ of DOXO-loaded micellar systems $(0.2 \mathrm{wt}$. \% copolymer) in $0.01 \mathrm{M}$ phosphate buffer $\mathrm{pH} 7.4,0.01 \mathrm{M}$ sodium citrate buffer $\mathrm{pH} 5.5$, or cell culture media at $\mathrm{pH} 7.4$ or 5.5 were placed into dialysis tubes (SpectraPore ${ }^{\circledR}$, MWCO 3500), and immersed into the same medium (500 $\mathrm{mL})$ used to prepare the micellar solutions. The medium was kept at $37^{\circ} \mathrm{C}$ and replaced every 6 hours to maintain sink conditions. The released drug concentration was spectrophotometrically 
monitored at $480 \mathrm{~nm}$, by removing a small volume $(20 \mu \mathrm{L})$ that was diluted in methanol in order to fit the calibration curve range. Assays were carried out in triplicate.

2.5. Copolymer cytocompatibility evaluation. The cytocompatibility of the bare copolymer micelles was first assessed using BALB/3T3 clone A31 mouse embryonic fibroblast cells (CCL 163, ATCC), following a previously reported procedure [23] (see Supplementary Material for further details).

2.6. Cellular uptake of DOXO after incubation with unimers and empty polymeric micelles ( $P$-gp inhibition). MDR NCI-ADR/RES and drug-sensitive MCF-7 cells (American Type Culture Collection, MD, USA) were separately seeded in a 24-wells plate $\left(1.5 \times 10^{5}\right.$ cells/well, $1000 \mu \mathrm{L} /$ well $)$ in supplemented RPMI 1640 and EMEM medium, respectively, for $48 \mathrm{~h}$. The medium was replaced by serum-free one containing 4-(2-hydroxyethyl)-1-piperazineethanesulfonic acid (HEPES, 25 mM, pH 7.4). Polymer samples were added $(20 \mu \mathrm{L}$; final concentrations in the medium $0.001 \%, 0.01 \%$ and $0.2 \%$ ) and cells incubated at $37^{\circ} \mathrm{C}$ for $30 \mathrm{~min}$. Polymer-free medium and VER solution $(100 \mu \mathrm{M})$ were used as blank and positive control, respectively. Immediately after 30 min incubation, $50 \mu \mathrm{l}$ of a DOXO solution $(100 \mathrm{mM}$ in water) was added and the samples incubated for 60 additional min. The medium was removed and the cells washed (PBS, 3 x $500 \mu \mathrm{L}$ ) to remove DOXO and copolymer residues. Quantification of DOXO inside the cells was carried out as previously reported [20] (see Supplementary Material for details). Confocal microscopy analysis (Leica TCS-SP2, LEICA Microsystems Heidelberg GmbH, Germany) was carried out upon cell staining with Bodipy ${ }^{\circledR}$ phalloidin $(30 \mu \mathrm{l} / \mathrm{ml})$ in $0.2 \%$ Triton $\mathrm{X}-100$ (permeabilizer), and subsequent washing and mounting on glass slides using anti-fading solution. Visualization was made at $20 \mathrm{X}$ and $63 \mathrm{X}$ using green channel for doxorrubicin $\left(\lambda_{\text {exc. }} 561 \mathrm{~nm}\right)$ and red channel for Bodipy® Phalloidin ( $\lambda_{\text {exc. }} 633 \mathrm{~nm}$, see Supplementary Material for details). 
2.7. Cellular uptake of calcein AM after incubation with the polymers. The calcein AM assay was performed following the method described by Dong et al. [24] (see Supplementary Material for details).

2.8. P-gp ATPase assay. The effect of $\mathrm{EO}_{33} \mathrm{SO}_{14} \mathrm{EO}_{33}, \mathrm{EO}_{38} \mathrm{SO}_{10} \mathrm{EO}_{38}$ and Pluronic $\mathrm{P} 85$ at $0.001 \%, 0.01 \%$ and $0.2 \mathrm{wt} \%$ on the ATPase activity of Pgp was measured using PgpGlo $^{\text {TM }}$ Assay System with P-glycoprotein (V3601, Promega Biotech Ibérica, SL, Madrid, Spain) following the manufacturer's protocol. $\mathrm{Na}_{3} \mathrm{VO}_{4}$ and verapamil $(12 \mu \mathrm{M})$ were used as controls of inhibition and stimulation, respectively. The luminescence of the samples detected using a Tecan Ultra Evolution (Tecan, Switzerland) reflected the ATP level, which negatively correlated with the activity of P-gp ATPase.

2.9. Cellular uptake of DOXO-loaded polymeric micelles (P-gp evasion). NCIADR/RES seeded in 24-wells plates ( $1 \times 10^{5}$ cells/well) in RPMI 1640 medium with 2 mM L-glutamine, 10\% FBS and 1\% penicillin/streptomycin over sterile glass covers. After 48 h, culture medium was replaced with RPMI 1640 medium with HEPES 25 mM ( $\mathrm{pH}$ 7.4). Cells were incubated with formulations containing DOXO for 1 and $24 \mathrm{~h}$ at $37^{\circ} \mathrm{C}$. Then, DOXO formulations were removed and the cells were washed and stained as explained above. As a control, the cells were incubated with DOXO solution $(50 \mu \mathrm{M})$ in PBS at pH 7.4.

2.10. In vitro cytotoxicity of drug loaded-polymeric micelles. Human NCI-ADR/RES and MCF-7 cells were seeded in 96-wells plates (15.000 cells/well) as described above. Then, DOXO-loaded micellar systems or DOXO·HCl solutions $(100 \mu \mathrm{M}$ and $50 \mu \mathrm{M}$ final concentration) in PBS pH 7.4 were added. As controls, copolymers at 0.01 and $0.2 \%$ (final concentrations) were used. Cytotoxicity was evaluated at 24 and $48 \mathrm{~h}$ applying the crystal violet method (see Supplementary Material for details). 


\section{Results and discussion}

The molecular characteristics of copolymers $\mathrm{EO}_{33} \mathrm{SO}_{14} \mathrm{EO}_{33}$ and $\mathrm{EO}_{38} \mathrm{SO}_{10} \mathrm{EO}_{38}$ and the physico-chemical properties of their micelles in diluted and concentrated regime were previously characterized in detail [25]. Briefly, $\mathrm{EO}_{33} \mathrm{SO}_{14} \mathrm{EO}_{33}$ and $\mathrm{EO}_{38} \mathrm{SO}_{10} \mathrm{EO}_{38}$ displayed very low cmc in aqueous medium $\left(2.5 \cdot 10^{-3}\right.$ and $3.7 \cdot 10^{-3}$ wt. $\%$, respectively), and formed monodisperse spherical micelles of ca. $13 \mathrm{~nm}$ in diameter and association numbers of 37 and 14, respectively (Table S1 and Fig. S1 in Supplementary Material).

3.1. Solubilization capacity. Some PSO-PEO block copolymers have shown superior solubilisation ability compared to Pluronic $^{\circledR}$ and Tetronic $^{\circledR}$ ones $[14,15,17]$. Optimization of the SO/EO ratio and the blocks length can enhance their perfomance. Apparent solubility of DOXO was tested in $0.2 \mathrm{wt} \%$ copolymer solutions (above the cmc) by adding different amounts of drug in order to evaluate the impact of the feeding amount on the entrapment efficiency and the total drug loaded. In general, the higher the drug/copolymer weight ratio, the lower the entrapment efficiency was (Table 2) due to drug saturation of the micelles. $\mathrm{EO}_{33} \mathrm{~S}_{14} \mathrm{EO}_{33}$ copolymer exhibited a slightly larger solubilisation capacity, which can be attributed to its longer hydrophobic block and subsequent higher affinity of the micelle core for hydrophobic drugs. Nevertheless, both copolymers encapsulated DOXO very efficiently with a hydrosolubility excess of 30 $\mathrm{mg} / \mathrm{l}$; i.e, more than 60 times the aqueous solubility of free DOXO. The maximum loading capacity was ca. $1.8 \%$, with entrapment efficiencies ranging from $20 \%$ to $50 \%$ depending on the drug feeding concentration. These values are also slightly larger than those reported for DOXO in previous solubilisation studies with other block copolymers, such as PEO-based poly(DL-lactic-co-glycolic acid), PEG-PLGA, poly(caprolactone), PEO-PCL, or poly[N-(2-hydroxypropyl) methacrylamide-lactate), 
PEG-p(HPMAm-Lac), that had entrapment efficiencies of ca. $23 \%, 48 \%$ or $5 \%$, respectively [26-30].

Table 2: Doxorubicin loaded amount (D.L.), entrapment efficiency (E.E.) and solubilisation capacity $\left(S_{C P}\right)$ of the copolymers at $0.2 \mathrm{wt} \%$.

\begin{tabular}{|c|c|c|c|c|c|c|}
\hline \multirow{2}{*}{$\begin{array}{c}\text { Feeding } \\
\text { drug/polymer } \\
\%(w / w)\end{array}$} & \multicolumn{3}{|c|}{$\mathrm{EO}_{33} \mathrm{SO}_{14} \mathrm{EO}_{33}$} & \multicolumn{3}{|c|}{$\mathrm{EO}_{38} \mathrm{SO}_{10} \mathrm{EO}_{38}$} \\
\hline & $\begin{array}{c}\text { D.L. } \\
\%\end{array}$ & $\begin{array}{c}\text { E.E. } \\
\%\end{array}$ & $\begin{array}{c}S_{c p} \\
m g q^{-1}\end{array}$ & $\begin{array}{c}\text { D.L. } \\
\%\end{array}$ & $\begin{array}{c}E . E . \\
\%\end{array}$ & $\begin{array}{c}S_{c p} \\
m g q^{-1}\end{array}$ \\
\hline 0.1 & 0.05 & 46.7 & 0.4 & 0.05 & 51.8 & 0.5 \\
\hline 0.5 & 0.2 & 52.3 & 2.4 & 0.2 & 46.0 & 2.2 \\
\hline 1 & 0.3 & 36.8 & 3.4 & 0.4 & 44.7 & 4.2 \\
\hline 2.75 & 1.0 & 37.6 & 10.2 & 1.0 & 38.6 & 10.5 \\
\hline 4.25 & 1.4 & 34.5 & 14.5 & 0.9 & 22.1 & 9.3 \\
\hline 6 & 1.8 & 30.8 & 16.1 & 1.3 & 21.2 & 11.6 \\
\hline
\end{tabular}

3.2. Size distribution and physical stability of DOXO-loaded polymeric micelles. Size is critical for the biodistribution profile and the interactions of micelles with cells. Drug incorporation could increase the micellar size due to either the enlargement of the core [31] and/or the fusion of drug-containing micelles into larger ones [32]. However, both non-loaded and DOXO loaded-micelles showed similar narrow and monodisperse intensity distribution functions by DLS. The loaded micelles could be readily freezedried and their initial size distribution was recovered upon reconstitution in aqueous solution (Fig. 1A). The micellar sizes also remained stable upon extensive incubation, which points to a great micelle stability and the capability of the PEO stealth layer to avoid protein binding and subsequent micellar aggregation (Fig. 1B and Supplementary Material, Fig. S2A).

DOXO-loaded-copolymer micellar solutions were strongly diluted (1/50) in medium with or without $10 \%$ FBS to mimic the events after body administration, and the drug concentration was monitored over time. In any tested medium, the loadedpolymeric micelles were physically stable until 10-12 days. DOXO solubility remained above $86 \%$ of the initial value for $\mathrm{EO}_{33} \mathrm{~S}_{14} \mathrm{EO}_{33}$ and ca. $75 \%$ for $\mathrm{EO}_{38} \mathrm{SO}_{10} \mathrm{EO}_{38}$ when 
incubating in the cell culture medium (Fig. 1C). In the absence of proteins, DOXO solubility remained slightly larger: ca. $92 \%$ and $85 \%$ for $\mathrm{EO}_{33} \mathrm{~S}_{14} \mathrm{EO}_{33}$ and $\mathrm{EO}_{38} \mathrm{SO}_{10} \mathrm{EO}_{38}$, respectively, at 20 days of incubation (Supplementary Material Fig. $\mathrm{S} 2 \mathrm{~B})$. The observed slightly lower stability of $\mathrm{EO}_{38} \mathrm{SO}_{10} \mathrm{EO}_{38}$ micelles possibly arises from a less compact/smaller hydrophobic core and higher cmc. In addition, the colloidal stability of $\mathrm{EO}_{33} \mathrm{SO}_{14} \mathrm{EO}_{33}$ and $\mathrm{EO}_{38} \mathrm{SO}_{10} \mathrm{EO}_{38}$ micelles is apparently larger than that previously reported for $\mathrm{EO}_{45} \mathrm{SO}_{15}$ and $\mathrm{EO}_{45} \mathrm{SO}_{26}$ diblock copolymers [18]; nevertheless, it is necessary to bear in mind that the latter copolymers were subjected to stronger destabilizing conditions which might accelerate their disintegration. Also, micellar stability of $\mathrm{EO}_{33} \mathrm{SO}_{14} \mathrm{EO}_{33}$ and $\mathrm{EO}_{38} \mathrm{SO}_{10} \mathrm{EO}_{38}$ is greater than that of some structurally related PBO-PEO and PPO-PEO block copolymers, for which the drug solubilized decreased more than $60 \%$ upon extended incubation $[18,23,32]$.

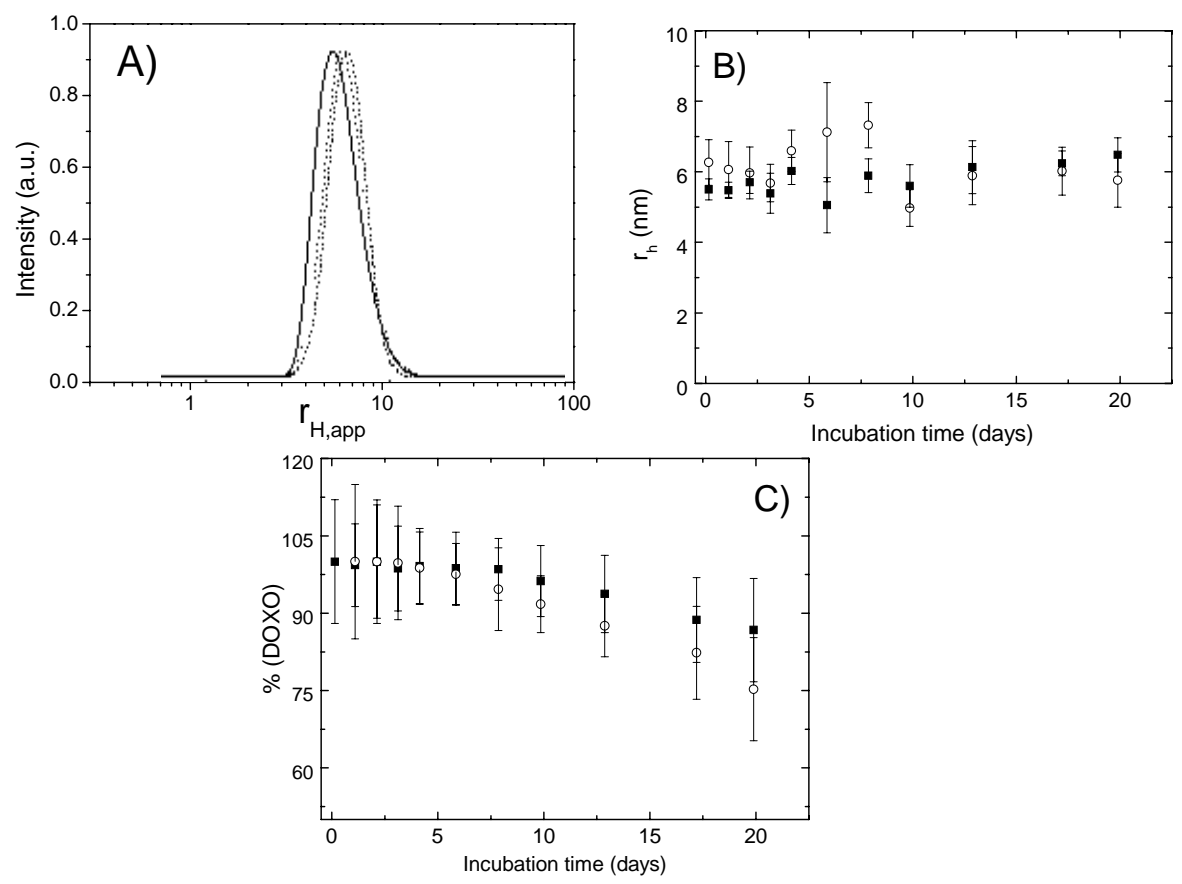

Fig. 1: Intensity fraction size distribution of (-) non-loaded, ( $\cdots)$ DOXO-loaded and (--) reconstituted freeze-dried DOXO-loaded $\mathrm{EO}_{33} \mathrm{SO}_{14} \mathrm{EO}_{33}$ micelles (A); temporal evolution of the size of DOXO-loaded $\mathrm{EO}_{33} \mathrm{SO}_{14} \mathrm{EO}_{33}(\boldsymbol{a})$ and $\mathrm{EO}_{38} \mathrm{SO}_{10} \mathrm{EO}_{38}(\mathrm{O})$ micelles under strong dilution in cell culture medium (B); and \%DOXO that remained solubilised in the polymeric micelles over time when diluted with cell culture medium at $37^{\circ} \mathrm{C}(\mathrm{C})$. 
3.3 In vitro release. DOXO-loaded micellar solutions ( 0.2 wt. $\%$ copolymer) were dialysed against pH 7.4 and 5.5 buffer and serum-containing (10\% FBS) media using dialysis tubing that ensured that no micellar diffusion occurred. In general, in vitro cumulative DOXO release profiles at both neutral and acidic conditions in the presence of FBS showed a burst followed by a sustained release pattern (Fig. 2). At pH 7.4, ca. $25 \%$ DOXO was released from both micellar systems in the first $5 \mathrm{~h}$ of incubation, and then a more sustained release was observed with ca. $35 \%$ released at $60 \mathrm{~h}$. In general, the amount of drug released from $\mathrm{EO}_{38} \mathrm{SO}_{10} \mathrm{EO}_{38}$ micelles was slightly larger than from the $\mathrm{EO}_{33} \mathrm{SO}_{14} \mathrm{EO}_{33}$ ones, probably as a consequence of the observed slightly lower micelle stability due to a less compact hydrophobic core of the former polymer, which may favor the formation of hydrophilic channels [32]. The drug release rate was higher at $\mathrm{pH}$ 5.5, which is consistent with previous reports [27,33-34] (for modellization of release profiles, see Supplementary Material). At $\mathrm{pH}$ 5.5, $\mathrm{EO}_{38} \mathrm{SO}_{10} \mathrm{EO}_{38}$ and $\mathrm{EO}_{33} \mathrm{SO}_{14} \mathrm{EO}_{33}$ micelles released, respectively, ca. $39 \%$ and $47 \%$ of the initially loaded DOXO during the first $5 \mathrm{~h}$ and ca. $76 \%$ and $63 \%$ at $60 \mathrm{~h}$. As occurred for the stability micellar tests, no significant differences in the release profiles were observed when serum was not present in the medium (Supplementary Material, Fig. S3). The faster release under acidic conditions is originated from the reprotonation of the amine group of DOXO, which involves an increase in its hydrophilicity and a decrease in the affinity for the hydrophobic blocks. This in turn favors its escape from the micellar core by an out-diffusion process through the core-shell structure whose diffusion rate depends on factors such as copolymer crystallinity, viscosity, and drug association state [35]. Reprotonation would enable DOXO to be preferentially released in acidic tumor sites, compared to healthy tissues. In this regard, it is plausible that copolymer micelles are passively targeted to the tumor tissue through the EPR effect with minimised DOXO 
release along circulation in the bloodstream. After accumulation in the vicinity of the tumor cells, DOXO could be selectively released from the micelles in the acidic solid tumor microenvironment for passive cellular uptake [33]. More importantly, intact copolymer micelles might be also taken up by tumor cells through nonspecific endocytosis and located preferentially at the acidic endosome compartments, in which the decreasing $\mathrm{pH}$ values might induce a faster DOXO release and a subsequent diffusion in the cytosol. This cellular uptake mechanism could bypass, to certain extent, the multidrug resistance (MDR) effect, which is often observed when free DOXO penetrates in the cell by passive diffusion.

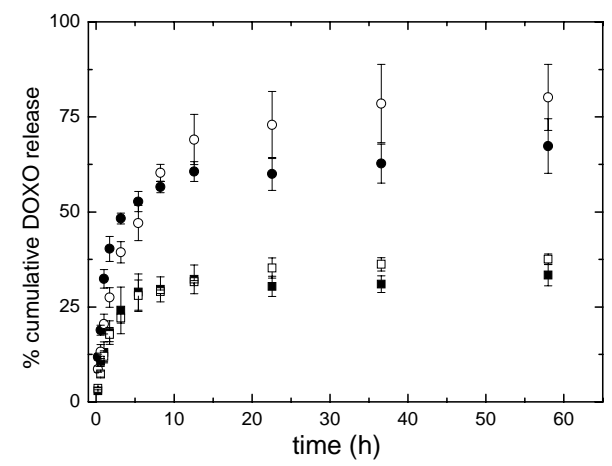

Fig. 2: In vitro drug release from DOXO-loaded $\mathrm{EO}_{33} \mathrm{SO}_{14} \mathrm{EO}_{33}$ (filled symbols) and $\mathrm{EO}_{38} \mathrm{SO}_{10} \mathrm{EO}_{38}$ (open symbols) micelles in cell culture medium (10\% FBS) at $\mathrm{pH} 7.4$ (squares) and 5.5 (circles).

3.4. Cytocompatibility of $\mathrm{EO}_{33} \mathrm{SO}_{14} \mathrm{EO}_{33}$ and $\mathrm{EO}_{38} \mathrm{SO}_{10} \mathrm{EO}_{38}$. Cytocompatibility tests were carried out against the BALB/3T3 fibroblast cell line because of its high sensitiveness to the presence of toxic species. The LDH assay enabled to measure if this cytosolic enzyme was released to the culture medium due to increased membrane permeability, indicating cell damage or lysis [36]. For the lowest concentration tested ( 0.1 wt.\%) viability extents of ca. $100 \%$ were observed for both copolymers, decreasing up to ca. $92 \%$ (for $\mathrm{EO}_{38} \mathrm{SO}_{10} \mathrm{EO}_{38}$ ) and $84 \%$ (for $\mathrm{EO}_{33} \mathrm{SO}_{14} \mathrm{EO}_{33}$ ) when copolymer concentration increased up to $1.66 \mathrm{wt} \%$ (Fig. 3). In order to prevent false positives caused by possible delayed LDH release from cells after induction of cell apoptosis or 
necrosis, the activity of the mitochondrial dehydrogenase enzyme was studied by means of the MTT assay. Whilst cell viability for $\mathrm{EO}_{33} \mathrm{SO}_{14} \mathrm{EO}_{33}$ was ca. $100 \%$ in the whole range of concentrations analyzed, proliferation in the presence of $\mathrm{EO}_{38} \mathrm{SO}_{10} \mathrm{EO}_{38}$ was lower and slightly decreased as the copolymer concentration increased: $95 \%$ at 0.1 wt. $\%, 82.5 \%$ at 1.0 wt. $\%$, to ca. $60 \%$ at a concentration of 1.66 wt. $\%$, respectively. In any case, none of the copolymer concentrations led to cell viabilities below $50 \%$ [37]. Therefore, both copolymers can be considered as safe and non-toxic, being even more cytocompatible than most of the commercially available and FDA-approved Pluronic ${ }^{\circledR}$ and Tetronic ${ }^{\circledR}$ block copolymers $[20,32]$.
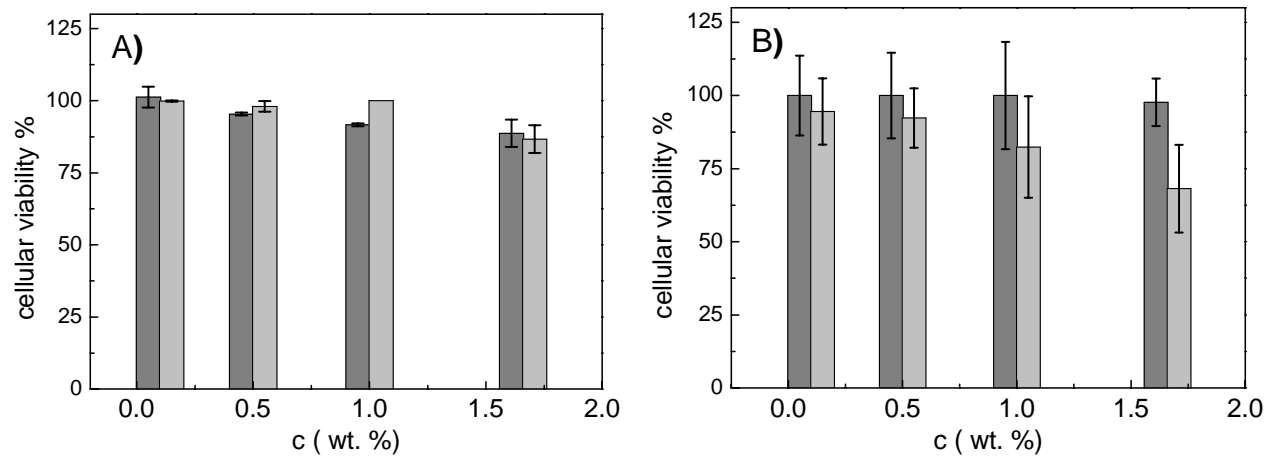

Fig. 3: Viability of BALB/3T3 fibroblasts exposed to $\mathrm{EO}_{33} \mathrm{SO}_{14} \mathrm{EO}_{33}$ (dark grey bars) and $\mathrm{EO}_{38} \mathrm{SO}_{10} \mathrm{EO}_{38}$ (light grey bars) solutions, measured by means of LDH (A) and MTT (B) assay. Mean \pm SD $(n=3)$.

\subsection{Inhibition of P-gp efflux pump and intracellular DOXO accumulation. Over-} expression in cancer cells of efflux transporters belonging to the ATP-binding casette proteins superfamily, such as P-gp and MDR-associated proteins (MDR phenotype), severely limits the efficacy of the chemotherapeutic treatments [19,38-39]. Efflux of drug molecules in the basolateral-to-apical direction leads to drug removal from the target organ or tissue, and results in subtherapeutic concentrations and very often in therapeutic failure. It has been reported that different PEO-PPO copolymers, such as Pluronic $^{\circledR}$ [8] or Tetronic ${ }^{\circledR}$ [20], PEO-PCL [40], and some natural polymers such as anionic gums and polysaccharides [41], effectively inhibit the activity of the efflux 
pumps and enhance the accumulation of their substrates in target tissues and organs. The interaction of the individual unimers with the lipid microenvironment surrounding P-gp and the copolymer induced-ATP depletion in MDR cells have been pointed out as possible mechanisms for chemosensitization of these cells [8]. We have evaluated the Pgp inhibitory performance of $\mathrm{EO}_{33} \mathrm{SO}_{14} \mathrm{EO}_{33}$ and $\mathrm{EO}_{38} \mathrm{SO}_{10} \mathrm{EO}_{38}$ by measuring the intracellular accumulation of DOXO (an exclusive substrate of P-gp) in the ovarian tumor cell line NCI-ADR-RES, which is an adequate in vitro model of MDR cells with a relatively high expression of P-gp [42], and also, for comparative purposes, in the drug-sensitive breast cancer cell line MCF-7. The inhibitory P-gp performance of the copolymers at 0.001 (below $\mathrm{cmc}$ ), 0.01 and $0.2 \mathrm{wt} \%$ (concentration used in solubilisation and drug release experiments) was assessed and compared with that attained with the well-characterized selective and efficient P-gp inhibitors verapamil, VER, [43] and Pluronic ${ }^{\circledR}$ P85 [8,19]. Preincubation of MCF-7 cells with any of the polymers or VER did not significantly increase (ANOVA, post-hoc T3 Dunnet) the intracellular accumulation of DOXO (Table S3 in Supplementary Material). Compared to the accumulation level achieved when DOXO solely solution was applied to the NCIADR-RES cells, the preincubation with VER $100 \mu \mathrm{M}$ led to a 2.12-fold increase in DOXO accumulation, $\mathrm{f}_{\mathrm{DOXO}}$. Preincubation of NCI-ADR-RES cells with $\mathrm{EO}_{33} \mathrm{SO}_{14} \mathrm{EO}_{33}$ and $\mathrm{EO}_{38} \mathrm{SO}_{10} \mathrm{EO}_{38}$ at 0.2 wt.\% increased DOXO accumulation by $1.58 \pm 0.18$ and 1.34 \pm 0.12 -fold, respectively. Preincubation with the polymers at 0.001 and $0.01 \mathrm{wt} . \%$ led to similar DOXO accumulation levels (Table S3 in Supplementary Material). DOXO accumulation levels were statistically higher $(\mathrm{P}<0.01$, ANOVA test, post-hoc $\mathrm{T} 3$ Dunnet) than those achieved without preincubation (only DOXO). In contrast, $\mathrm{EO}_{33} \mathrm{SO}_{14} \mathrm{EO}_{33}$ and $\mathrm{EO}_{38} \mathrm{SO}_{10} \mathrm{EO}_{38}$ did no increase the accumulation of calcein-AM, a lipid soluble dye recognized as a substrate for both P-gp and MRP transporters [44], 
which highlights the complexity of the different efflux pumps mechanisms and their interrelation (see Supplementary Material for details on calcein-AM accumulation studies).

To gain further insight into the mechanism by which $\mathrm{EO}_{33} \mathrm{SO}_{14} \mathrm{EO}_{33}$ and $\mathrm{EO}_{38} \mathrm{SO}_{10} \mathrm{EO}_{38}$ enhanced DOXO accumulation in the P-gp overexpressed cells, the Pgp ATPase activity was recorded. VER is a potent P-gp substrate that leads to ATP consumption and caused $2.68 \pm 0.37$-fold increase in ATPase activity compared to the basal activity registered in the presence of ortovanadate, which is in agreement with previous results. [45]. This effect is the opposite of that recorded for Pluronic P85, which below $0.01 \%$ led to a decrease in ATPase activity to the half. As previously observed [19], the effect of Pluronic P85 on P-gp ATPase disappeared at $0.2 \%$, indicating that only the unimers are able to inhibit the activity. Interestingly, $\mathrm{EO}_{38} \mathrm{SO}_{10} \mathrm{EO}_{38}$ and, more remarkably, $\mathrm{EO}_{33} \mathrm{SO}_{14} \mathrm{EO}_{33}$ behaved as Pluronic P85 (Table S3 in Supplementary Material). Namely they inhibited P-gp ATPase. The stronger inhibitory effect of $\mathrm{EO}_{33} \mathrm{SO}_{14} \mathrm{EO}_{33}$, even greater than for Pluronic P85, could be related to its greater hydrophobicity and, thus, to an enhanced ability to alter the conformation of the efflux protein and the ATP-binding domains [19]. In the case of $\mathrm{EO}_{38} \mathrm{SO}_{10} \mathrm{EO}_{38}$, the inhibitory effect increased from $0.001 \%$ to $0.01 \%$ and then leveled off, which is also typical of an unimer concentration-dependent inhibitory effect [19].

Although the P-gp inhibitory effect has been found to be stronger at copolymer concentrations close to the cmc $[19,20]$, we have not observed a detrimental effect on DOXO accumulation when the copolymers concentration raised from 0.001 to $0.2 \mathrm{wt} . \%$ (Table S3 in Supplementary Material), which in terms of successful pharmacotherapy, may be benefitial because of the greater ability of copolymers at $0.2 \mathrm{wt} . \%$ (due to the larger number of micelles available) to solubilize the drug inside the polymeric micelles 
and act as efficient drug carriers. At this latter concentration, $\mathrm{EO}_{38} \mathrm{SO}_{10} \mathrm{EO}_{38}$ and $\mathrm{EO}_{33} \mathrm{SO}_{14} \mathrm{EO}_{33}$ unimers in equilibrium with the micelles might be enough to inhibit the P-gp pump.

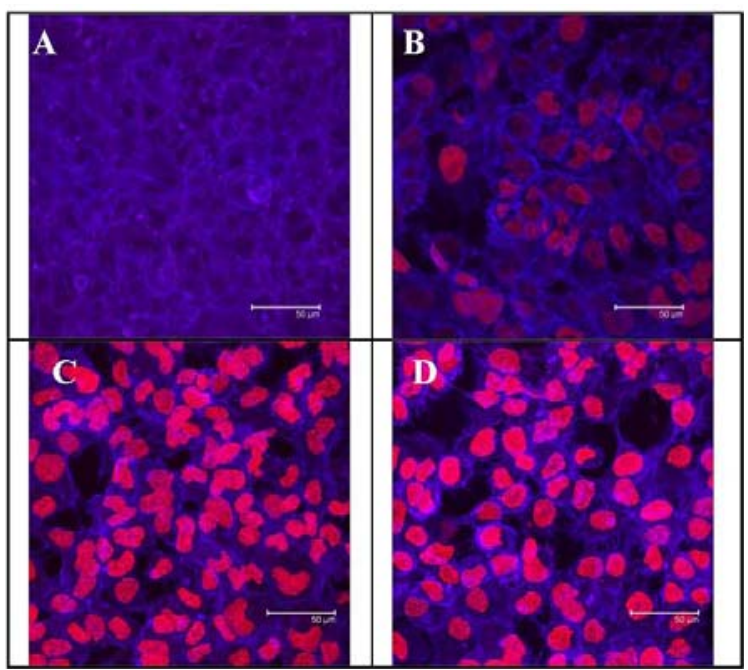

Fig. 4: Confocal microscopy images of NCI-ADR-RES cells alone (A); in the presence of $50 \mu \mathrm{M}$ DOXO (B); pretreated with $100 \mu \mathrm{M}$ VER (C), and with 0.2 wt.\% $\mathrm{EO}_{33} \mathrm{SO}_{14} \mathrm{EO}_{33}(\mathrm{D})$ and then incubated with $50 \mu \mathrm{M}$ DOXO. Scale bar $50 \mu \mathrm{m}$.

To evaluate the integrity of the NCI-ADR-RES monolayers and qualitatively assess the localization and intensity of DOXO inside cells, cells preincubated with 0.2 wt.\% copolymer and, then, treated with DOXO solely solutions were observed under confocal microscopy (Fig. 4). All the specimens showed the nuclear localization of DOXO [46]. Cells exposed to VER or to the copolymers were more stained than the non-pretreated cells, confirming that DOXO efflux was inhibited to some extent. The relatively similar fluorescence intensity provided by the DOXO/VER and the $\mathrm{DOXO} /$ copolymer systems is in agreement with the quantitative analysis described above that showed no statistical differences in the accumulated DOXO between the systems.

3.6. Cellular uptake and in vitro cytotoxicity of DOXO-loaded polymeric micelles (P-gp evasion). In order to avoid DOXO cardiotoxicity and to enhance its chemotherapeutic activity, it is crucial to deliver the drug and to sustain its release in the cytoplasm and 
right into the nucleus of cancerous cells. We tested the cellular uptake of DOXO-loaded polymeric micelles in the NCI-ADR-RES cell line at $37{ }^{\circ} \mathrm{C}$ and compared to that achieved with free DOXO solely solutions at 1 and $24 \mathrm{~h}$ after incubation (Fig. 5 and Supplementary Material Fig. S4). After exposure of the cells to free DOXO, drug accumulation was rapid but limited. DOXO fluorescence intensity after $24 \mathrm{~h}$ incubation in the presence of free drug was rather lower than after 1h. Free DOXO may cross the cell membrane by passive diffusion, a pathway that in MDR NCI-ADR-RES cells is affected by P-gp. The observations suggest that DOXO previously uptaken was extruded out of NCI-ADR-RES cells by the P-gp efflux pump. On the contrary, for the DOXO-containing polymeric micelles, drug accumulation increased as a function of time. Low accumulation inside the cells at short incubation times (1 h, Fig. S4) can be related to the relatively low release of DOXO from the micelles at such time (see Fig. 2). Confocal images after $24 \mathrm{~h}$ of cell incubation in the presence of the drug-loaded polymeric formulations showed an important increase in the drug fluorescence staining inside the cells as a consequence of DOXO accumulation after micelle release. It has been previously shown that as a result of the self-quenching effect of DOXO in nanoparticles, fluorescence is only observed when DOXO is released [47]. A more intense fluorescence is noted for larger drug concentrations entrapped in the polymeric micelle cores (see Fig. 5). The spotty fluorescence pattern observed for the drug loaded in the polymeric formulations is typical of cytoplasmatic localization of the drug, in contrast to a more intense and continuous pattern observed for usual nuclear accumulation of free DOXO. This suggests that DOXO-loaded micelles might be taken up by an endocytosis-mediated mechanism, being initially located within the endosome vesicles, and enabling DOXO release in the cytosol in a sustained manner due to the endosome acidic environment. At the same time, micelle escape from endosomes and 
transport to cytoplasmatic organelles could contribute to the observed spotty fluorescence pattern [48]. In contrast, free DOXO would be transported into cells via a passive diffusion mainly from the cytosol to the nucleus where would be avidly bound to the chromosomal DNA, generating the continuous fluorescence pattern [35].

Finally, the cytotoxicity of the DOXO-loaded polymeric micelles in NCI-ADRRES and MCF-7 tumoral cell lines was evaluated applying the crystal violet method (Fig. 6 A and B). This procedure correlates well with others such as the MTT assay, which could not be used in this case because DOXO interferes in the formation of formazan crystals and make the assay unreliable [48]. As a control, we have previously tested the potential cytotoxicity of the empty polymeric micelles of $\mathrm{EO}_{33} \mathrm{SO}_{14} \mathrm{EO}_{33}$ and $\mathrm{EO}_{38} \mathrm{SO}_{10} \mathrm{EO}_{38}$ in these cancerous cell lines. Both block copolymers were observed to be safe and non-toxic, with NCI-ADR-RES and MCF-7 viabilities larger than $95 \%$ after $24 \mathrm{~h}$ of incubation. The viability of NCI-ADR-RES cells scarcely decreased to ca. $87 \%$ after $48 \mathrm{~h}$ of incubation with $\mathrm{EO}_{33} \mathrm{SO}_{14} \mathrm{EO}_{33}$ at the highest concentration tested (1.66 wt.\%, see Fig. S5 in Supplementary Material), in agreement with the results obtained with murine fibroblasts (Fig. 3). MCF-7 cells resulted to be slightly more sensitive; $\mathrm{EO}_{33} \mathrm{SO}_{14} \mathrm{EO}_{33}$ and $\mathrm{EO}_{38} \mathrm{SO}_{10} \mathrm{EO}_{38}$ at 0.2 wt.\% led to $21 \%$ and $17 \%$ inhibition of cell growth after $48 \mathrm{~h}$ of incubation (Fig. 6B). Pluronic P85 placebo micelles (0.2 wt.\%) resulted to be more cytotoxic and caused $37 \%$ and $77 \%$ inhibition of NCI-ADR-RES cell growth (Fig. 6A) and 16\% and 61\% inhibition of MCF-7 cell growth after $24 \mathrm{~h}$ and 48 h of incubation, respectively (Fig. 6B). Growth inhibition caused by Pluronic P85 itself is in agreement with previous reports and related to damage in cell membrane [49]. 


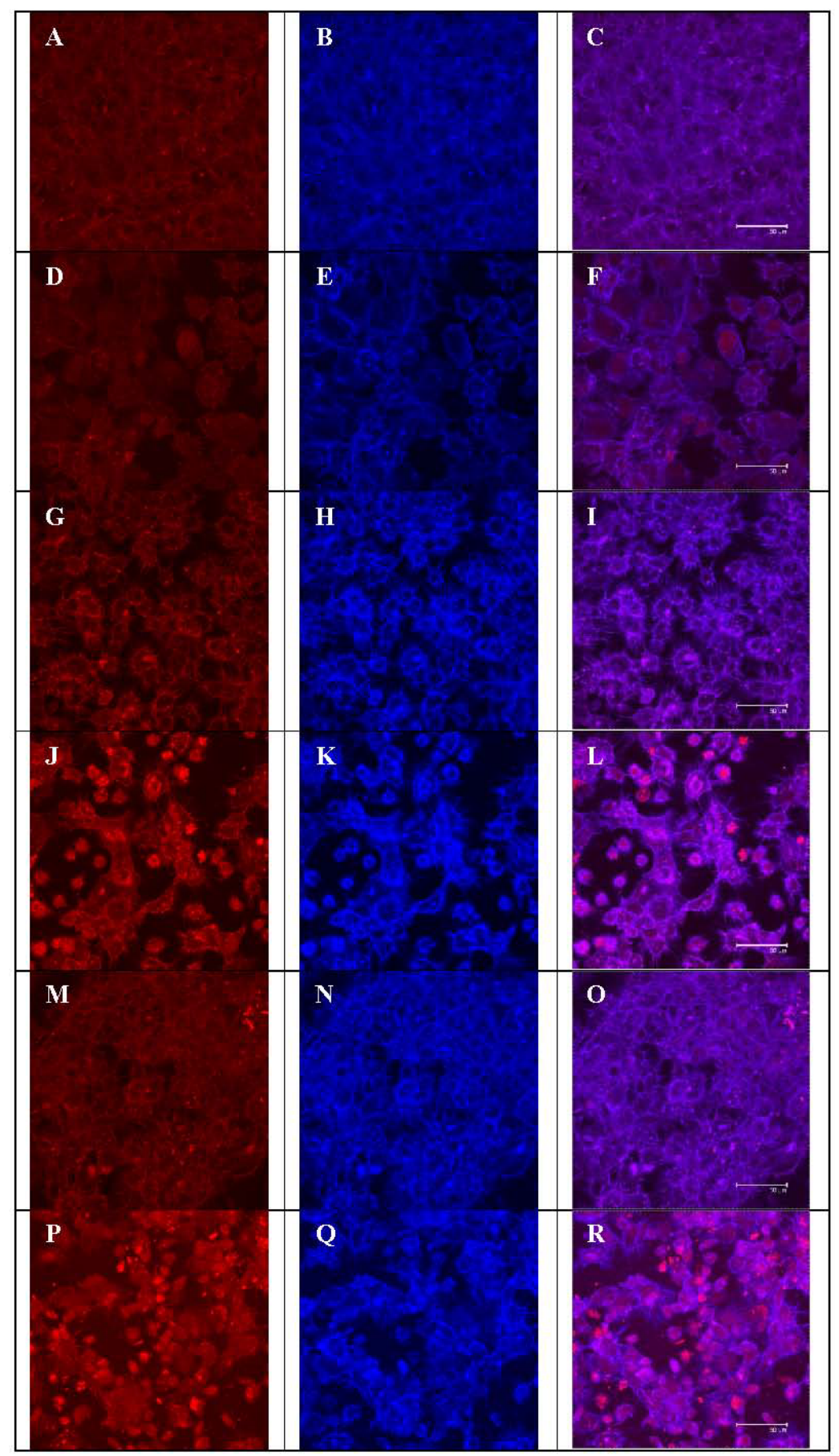

Fig. 5: Confocal microscopy images recorded using a DOXO (left column) or a Bodipy ${ }^{\circledR}$ Phalloidin (middle column) filter, and superimposed images (right column) of NCI-ADR-RES cells after $24 \mathrm{~h}$ of incubation in culture medium solely (A-C, control); with $50 \mu \mathrm{M}$ free DOXO (D-F); with 0.2 wt. \% $\mathrm{EO}_{33} \mathrm{SO}_{14} \mathrm{EO}_{33}$ micelles loaded with 10 $\mu \mathrm{M}$ DOXO (G-I) or $50 \mu \mathrm{M}$ DOXO (J-L), and with 0.2 wt. $\% \mathrm{EO}_{38} \mathrm{SO}_{10} \mathrm{EO}_{38}$ micelles loaded with $10 \mu \mathrm{M}$ DOXO (M-O) or $50 \mu \mathrm{M}$ DOXO (P-R). Scale bar $50 \mu \mathrm{m}$. 

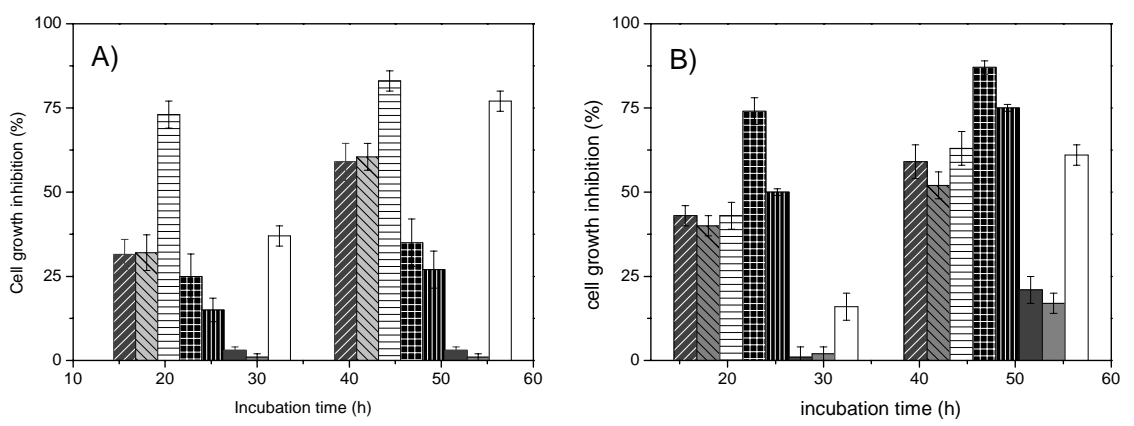

Fig. 6: Growth inhibition of NCI-ADR-RES (A) and MCF-7 (B) cells exposed to polymeric micelles $(0.2$ wt.\%) loaded with $50 \mu \mathrm{M}$ DOXO, or to $50 \mu \mathrm{M}$ and $100 \mu \mathrm{M}$ free DOXO solutions. From left to right, columns correspond to DOXO-loaded $\mathrm{EO}_{33} \mathrm{SO}_{14} \mathrm{EO}_{33}$ micelles, DOXO-loaded $\mathrm{EO}_{38} \mathrm{SO}_{10} \mathrm{EO}_{38}$ micelles, DOXO-loaded Pluronic P85 micelles, $100 \mu \mathrm{M}$ free DOXO, $50 \mu \mathrm{M}$ free DOXO, empty $\mathrm{EO}_{33} \mathrm{SO}_{14} \mathrm{EO}_{33}$ micelles, empty $\mathrm{EO}_{38} \mathrm{SO}_{10} \mathrm{EO}_{38}$ micelles, and empty Pluronic P85 micelles, respectively. Mean $\pm \operatorname{SD}(\mathrm{n}=3)$.

The enhancement in cell toxicity observed upon incubation with DOXO-loaded polymeric micelles can be ascribed to the cytotoxic effect of the loaded drug. In particular, the cytotoxic activity of the DOXO-loaded $\mathrm{EO}_{33} \mathrm{SO}_{14} \mathrm{EO}_{33}$ and $\mathrm{EO}_{38} \mathrm{SO}_{10} \mathrm{EO}_{38}$ micelles increased from $24 \mathrm{~h}$ to $48 \mathrm{~h}$ of incubation, which strongly supports the idea that both the sustained release and increased intracellular accumulation of DOXO leads to a more pronounced cell death. The growth inhibition of NCI-ADR-RES cells doubled from $24 \mathrm{~h}$ (ca. $30 \%$ inhibition) to $48 \mathrm{~h}$ (ca. $60 \%$ inhibition) (Fig. 6A), which is compatible with an increased accumulation inside the cell and a subsequent sustained drug release from the micelles. The cytotoxicity of the drug-loaded polymeric micelles was also larger than that of free DOXO solutions in NCI-ADR-RES cells, even when the free drug concentration was greater than that encapsulated inside micelles [35]. No significant differences in cell toxicity were observed between the two copolymers. The highest cytotoxicity recorded for DOXOloaded Pluronic P85 micelles can be related to the concomitance of the drug internalization and the marked deleterious effect of this copolymer on NCI-ADR-RES cells (Fig. 6A). As expected, MCF-7 cells resulted to be more sensitive to the treatment 
with DOXO, both free or encapsulated in the polymeric micelles (Fig. 6B). The $\mathrm{IC}_{50}$ values of DOXO for both cell lines at 24 and $48 \mathrm{~h}$ are summarized in Table S4.

Provided that both $\mathrm{EO}_{33} \mathrm{SO}_{14} \mathrm{EO}_{33}$ and $\mathrm{EO}_{38} \mathrm{SO}_{10} \mathrm{EO}_{38}$ are highly cytocompatible, DOXO carried by the polymeric micelles would enter the cells most likely via internalization followed by entrapment of the micelles in endosomes/lysosomes. In this way, the drug may evade the P-gp pumps, favoring its cellular accumulation and, hence, increasing the cytotoxic activity when released from the polymeric micelles [37]. The enhanced cytotoxicity of the drug-loaded micelles might be originated from both the endocytic intracellular transport [41], which increases the drug cellular uptake, and the contribution of the polystyrene oxide-based block copolymers to the sensitization of cells, favoring DOXO-induced apoptotic cell death, as reported for Pluronic ${ }^{\circledR}$ and its derivatives $[12,20,21,41,46]$.

\section{Conclusion}

The results obtained here with the present PEO-PSO block copolymers highlight the role of a judicious choice of the hydrophobic block and the relative block lengths to achieve a successful cytotoxic effect of the drug-loaded polymeric nanocarriers on cancer cells. Aqueous solutions of block copolymers $\mathrm{EO}_{33} \mathrm{SO}_{14} \mathrm{EO}_{33}$ and $\mathrm{EO}_{38} \mathrm{SO}_{10} \mathrm{EO}_{38}$ self-assemble at very low concentrations to form cytocompatible spherical micelles suitable for sterilizing filtration and administration by parenteral route. These polymeric micelles efficiently entrap DOXO and display a release profile with an initial burst phase at very short times followed by a more sustained rate. The observed $\mathrm{pH}$ dependent release may prompt drug accumulation in tumoral tissues due to the acidic $\mathrm{pH}$ conditions in both cell membrane surroundings (caused by hypoxia) and in some intracellular compartments (i.e., lysosomes). The cytotoxic activity of the DOXOloaded polymeric micelles is exclusively ascribed to the DOXO therapeutic action. 
Confocal microscopy images showed that DOXO progressively accumulates inside the MDR cells (evading efflux pumps), prolonging their residence inside and, consequently, enhancing cytotoxicity over that observed for free DOXO solutions. Moreover, $\mathrm{EO}_{33} \mathrm{SO}_{14} \mathrm{EO}_{33}$ and $\mathrm{EO}_{38} \mathrm{SO}_{10} \mathrm{EO}_{38}$ unimers have certain ability to inhibit P-gp efflux pump, as occurs for some Pluronic ${ }^{\circledR}$ and Tetronic ${ }^{\circledR}$ block copolymers. Hence, the role of the present copolymers evolve from plain "inert drug nanocarriers" to relevant "biological response inducers" as a consequence of complementation of the drugcytotoxic activity with a moderate inhibition of the P-gp activity, which highlights the complexity of the cell response to the presence of the block copolymer micelles.

\section{Acknowledgements}

Work supported by Ministerio de Ciencia e Innovación (MICINN; MAT 2010-17336 and SAF 2011-22771), Xunta de Galicia (INCITE09206020PR), European Regional Development Funds (research project 2010/50), and Fundación Ramón Areces. The authors thank M.I. Cadavid for help during planning and discussion of cell assays and R. Piña for technical support in doxorubicin cellular uptake experiments.

\section{Appendix A. Supplementary material}

Supplementary materials can be found, in the online version, at http://dx.doi.org/10.1016/j.jconrel.2012.

\section{References}

[1] O.C. Farokhzad, R. Langer, Nanomedicine: Developing smarter therapeutic and diagnostic modalities. Adv. Drug Deliv. Rev. 58 (2006) 1456-1459.

[2] P.-Y. Lee, K.K.Y. Wong, Nanomedicine: a new frontier in cancer therapeutics. Current Drug Deliv. 8 (2011) 245-253.

[3] J. Heidel, M. Davis, Clinical developments in nanotechnology for cancer therapy. Pharm. Res. 28 (2011) 187-199.

[4] S. Ming, Y. Huang, L. Han, J. Qin, X. Fang, J. Wang, V.C. Yang, Multifunctional drug delivery system for targeting tumor and its acidic environment. J. Control. Release 161 (2012) 884-892. 
[5] E. Markovsky, H. Baabur-Cohen, A. Eldar-Boock, L. Omer, G. Tiram, S. Ferber et al. Administration, distribution, metabolism and elimination of polymer therapeutics. J. Control. Release 161 (2012) 446-460.

[6] N. Wiradharma, Y. Zhang, S. Venkataraman, J.L. Hedrick, Y.Y. Yang, Selfassembled polymer nanostructures for delivery of anticancer therapeutics. Nano Today 4 (2009) 302-317.

[7] A.V. Kabanov, V.Y. Alakhov, Pluronic block copolymers in drug delivery: from micellar nanocontainers to biological response modifiers. Crit. Rev. Ther. Drug Carrier Syst. 19 (2002) 1-72.

[8] E.V. Batrakova, A.V. Kabanov, Pluronic block copolymers: Evolution of drug delivery concept from inert nanocarriers to biological response modifiers. J. Control. Release 130 (2008) 98-106.

[9] C. Alvarez-Lorenzo, A. Sosnik, A. Concheiro, PEO-PPO block copolymers for passive micellar targeting and overcoming multidrug resistance in cancer therapy. Current Drug Targets 12 (2011) 1112-1130.

[10] Z. Yang, M. Crothers, N.M.P.S. Ricardo, C. Chaibundit, P. Taboada, V. Mosquera et al. Micellization and gelation of triblock copolymers of ethylene oxide and styrene oxide in aqueous solution. Langmuir 19 (2003) 943-950

[11] P. Taboada, G. Velasquez, S. Barbosa, V. Castelletto, S.K. Nixon, Z. Yang et al. Block copolymers of ethylene oxide and phenyl glycidyl ether: micellization, gelation, and drug solubilization. Langmuir 21 (2005) 5263-5271.

[12] C. Booth, D. Attwood, C. Price, Self-association of block copoly(oxyalkylene)s in aqueous solution. Effects of composition, block length and block architecture. Phys. Chem. Chem. Phys. 8 (2006) 3612-3622.

[13] S. Barbosa, M.A. Cheema, P. Taboada, V. Mosquera, Effect of copolymer architecture on the micellization and gelation of aqueous solutions of copolymers of ethylene oxide and styrene oxide. J. Phys. Chem. B 111 (2007) 10920-10928.

[14] M.E.N.P. Ribeiro, Í.G.P. Vieira, I.M. Cavalcante, N.M.P.S. Ricardo, D. Attwood, S.G. Yeates et al. Solubilisation of griseofulvin, quercetin and rutin in micellar formulations of triblock copolymers $\mathrm{E}_{62} \mathrm{P}_{39} \mathrm{E}_{62}$ and $\mathrm{E}_{137} \mathrm{~S}_{18} \mathrm{E}_{137}$. Int. J. Pharm. 378 (2009) 211-214.

[15] M. Crothers, Z. Zhou, N.M.P.S. Ricardo, Z. Yang, P. Taboada, C. Chaibundit et al. Solubilisation in aqueous micellar solutions of block copoly(oxyalkylene)s. Int. J. Pharm. 293 (2005) 91-100

[16] J. Juárez, P. Taboada, M.A. Valdez, V. Mosquera, Self-Assembly process of different poly(oxystyrene)-poly(oxyethylene) block copolymers: spontaneous formation of vesicular structures and elongated micelles. Langmuir 24 (2008) 7107-7116.

[17] M. Crothers, N.M.P.S. Ricardo, F. Heatley, S.K. Nixon, D. Attwood, C. Booth, Solubilisation of drugs in micellar solutions of diblock copolymers of ethylene oxide and styrene oxide. Int. J. Pharm. 358 (2008) 303-306.

[18] M. Elsabahy, M.-È. Perron, N. Bertrand, G.-E. Yu, J.-C. Leroux, Solubilization of docetaxel in poly(ethylene oxide)-block-poly(butylene/styrene oxide) micelles. Biomacromolecules 8 (2007) 2250-2257.

[19] E.V. Batrakova, S. Li, Y.L. Li, V.Y. Alakhov, A.V. Kabanov, Effect of pluronic P85 on ATPase activity of drug efflux transporters. Pharm. Res. 21 (2004) 22262233. 
[20] C. Alvarez-Lorenzo, A. Rey-Rico, J. Brea, M.I. Loza, A. Concheiro, A. Sosnik, Inhibition of P-glycoprotein pumps by PEO-PPO amphiphiles: branched versus linear derivatives. Nanomedicine 5 (2010) 1371-1383.

[21] Y. Yamamoto, Y. Nagasaki, Y. Kato, Y. Sugiyama, K. Kataoka, Longcirculating poly(ethylene glycol)-poly(d,l-lactide) block copolymer micelles with modulated surface charge. J. Control. Release 77 (2001) 27-38.

[22] S.H. Yalkowsky, Y. He, Handbook of aqueous solubility data. Boca Raton: CRC Press, 2003.

[23] D.A. Chiappetta, C. Alvarez-Lorenzo, A. Rey-Rico, P. Taboada, A. Concheiro, A. Sosnik, N-alkylation of poloxamines modulates micellar assembly and encapsulation and release of the antiretroviral efavirenz. Eur. J. Pharm. Biopharm. 76 (2010) 24-37

[24] X. Dong, C.A. Mattingly, M.T. Tseng, M.J. Cho, Y. Liu, V.R. Adams et al. Doxorubicin and paclitaxel-loaded lipid-based nanoparticles overcome multidrug resistance by inhibiting P-glycoprotein and depleting ATP. Cancer Res. 69 (2009) 3918-3926.

[25] A. Cambón, S. Barbosa, A. Rey-Rico, E. Figueroa-Ochoa, J.F.A. Soltero, S.G. Yeates et al. Poly(ethylene oxide)-poly(styrene oxide)-poly(ethylene oxide) copolymers: micellization, drug solubilisation and gelling features. J. Colloid Interface Sci. doi:10.1016/j.jcis.2012.06.090.

[26] H.S. Yoo, T.G. Park, Biodegradable polymeric micelles composed of doxorubicin conjugated PLGA-PEG block copolymer. J. Control. Release 70 (2001) 63-70.

[27] X. Shuai, H. Ai, N. Nasongkla, S. Kim, J. Gao, Micellar carriers based on block copolymers of poly(e-caprolactone) and poly(ethylene glycol) for doxorubicin delivery. J. Control. Release 98 (2004) 415-426.

[28] Y.-Y. Diao, H.Y. Li, Y.H. Fu, M. Han, Y.L. Hu, H.L. Jian et al. Doxorubicinloaded PEG-PCL copolymer micelles enhance cytotoxicity and intracellular accumulation of doxorubicin in adriamycin-resistant tumor cells. Int. J. Nanomed. 6 (2011) 1955-1962.

[29] M. Talelli, M. Iman, A.K. Varkouhi, C.J.F. Rijcken, R.M. Schiffeler, T. Etrych et al. Core-crosslinked polymeric micelles with controlled release of covalently entrapped doxorubicin. Biomaterials 31 (2010) 7797-7804.

[30] Y.-Y. Diao, M. Han, P.-T. Ding, D.-W. Chen, J.-Q. Gao, DOX-loaded PEGPLGA and Pluronic copolymer composite micelles enhances cytotoxicity and the intracellular accumulation of drug in DOX-resistant tumor cells. Die Pharmazie - Int. J. Pharm. Sci. 65 (2010) 356-358.

[31] G. Riess, Micellization of block copolymers. Progress Polym Sci 28 (2003) 1107-1170.

[32] Z. Wei, J. Hao, S. Yuan, Y. Li, W. Juan, X. Sha et al. Paclitaxel-loaded Pluronic P123/F127 mixed polymeric micelles: Formulation, optimization and in vitro characterization. Int. J. Pharm. 376 (2009) 176-185.

[33] Y. Lee, S.Y. Park, H. Mok, T.G. Park, Synthesis, characterization, antitumor activity of pluronic mimicking copolymer micelles conjugated with doxorubicin via acid-cleavable linkage. Bioconjug. Chem. 19 (2007) 525-531.

[34] J. Kim, J.E. Lee, S.H. Lee, J.H. Yu, J.H. Lee, T.G. Park et al. Designed fabrication of a multifunctional polymer nanomedical platform for simultaneous cancer- targeted imaging and magnetically guided drug delivery. Adv. Mater. 20 (2008)478-483. 
[35] M.L. Forrest, C.-Y. Won, A.W. Malick, G.S. Kwon. In vitro release of the mTOR inhibitor rapamycin from poly(ethylene glycol)-b-poly( $\varepsilon$-caprolactone) micelles. J. Control. Release 103 (2006) 370-377.

[36] T. Decker, M.-L. Lohmann-Matthes, A quick and simple method for the quantitation of lactate dehydrogenase release in measurements of cellular cytotoxicity and tumor necrosis factor (TNF) activity. J. Immunol. Methods 115 (1988) 61-69.

[37] M.E. Cavet, K.L. Harrington, K.R. Vandermeid, K.W. Ward, J.-Z. Zhang, Comparison of the effect of multipurpose contact lens solutions on the viability of cultured corneal epithelial cells. Contact Lens Ant. Eye 32 (2009) 171-175.

[38] R. Montesinos, A. Béduneau, Y. Pellequer, A. Lampretch, Delivery of Pglycoprotein substrates using chemosensitizers and nanotechnology for selective and efficient therapeutic outcomes. J. Control. Release 161 (2012) 50-61

[39] C.Y. Wu, L.Z. Benet, Predicting drug disposition via application of BCS: transport/absorption/elimination interplay and development of a biopharmaceutics drug disposition classification system. Pharm. Res. 22 (2005) $11-23$.

[40] J.A. Zastre, J.K. Jackson, W. Wong, H.M. Burt. P-glycoprotein efflux inhibition by amphiphilic diblock copolymers: relationship between copolymer concentration and substrate hydrophobicity. Mol. Pharm. 5 (2008) 643-653.

[41] M. Werle, Natural and synthetic polymers as inhibitors of drug efflux pumps. Pharm. Res. 25 (2008) 500-511.

[42] A.V. Roschke, G. Tonon, K.S. Gehlhaus, N. McTyre, K.J. Bussey, S. Labadidi et al. Karyotypic complexity of the NCI-60 drug-screening panel. Cancer Res. 63 (2003) 8634-8647.

[43] M.D. Kars, O.D. Iseri, U. Gunduz, J. Molnar. Reversal of multidrug resistance by synthetic and natural compounds in drug-resistant MCF-7 cell lines. Chemotherapy 54 (2008) 194-200.

[44] P. Limtrakul, W. Chearwae, S. Shukla, C. Phisalphong, S.V. Ambudkar, Modulation of function of three $\mathrm{ABC}$ drug transporters, P-glycoprotein (ABCB1), mitoxantrone resistance protein (ABCG2) and multidrug resistance protein 1 (ABCC1) by tetrahydrocurcumin, a major metabolite of curcumin. Mol. Cell Biochem. 296 (2007) 85-95F.

[45] T. Litman, T. Zeuthen, T. Skovsgaard, W.D. Stein. Competitive, non-competitive and cooperative interactions between substrates of P-glycoprotein as measured by its ATPase activity. Biochim. Biophys. Acta 1361 (1997)169-176.

[45] Shen, S. Chu, A.K. Bence, B. Bailey, X. Xue, P.A. Erickson et al. Quantitation of doxorubicin uptake, efflux, and modulation of multidrug resistance (MDR) in MDR human cancer cells. J. Pharmacol. Exp. Ther. 324 (2008) 95-102.

[46] Y.-L. Li, L. Zhu, Z. Liu, R. Cheng, F. Meng, J.-H. Cui et al. Reversibly stabilized multifunctional dextran nanoparticles efficiently deliver doxorubicin into the nuclei of cancer cells. Angew. Chem. Int. Ed. 48 (2009) 9914-9918.

[47] R. Savić, L. Luo, A. Eisenberg, D. Maysinger, Micellar nanocontainers distribute to defined cytoplasmic organelles. Science 300 (2003) 615-618.

[48] A.C. Collier, C.A. Pritsos, The mitochondrial uncoupler dicumarol disrupts the MTT assay. Biochem. Pharmacol. 66 (2003) 281-287.

[49] A.A. Exner, T.M. Krupka, K. Scherrer, J.M. Teets. Enhancement of carboplatin toxicity by Pluronic block copolymers, J. Control. Release 106, (2005) 188-197. 